\title{
XXXI. On the laws of mortality, and the intensity of human life
}

\section{Mr. Francis Corbaux}

To cite this article: Mr. Francis Corbaux (1829) XXXI. On the laws of mortality, and the intensity of human life , Philosophical Magazine Series 2, 5:27, 198-205, DOI: 10.1080/14786442908674961

To link to this article: http://dx.doi.org/10.1080/14786442908674961

册 Published online: 14 Jul 2009.

Submit your article to this journal $₫$

Џ Article views: 2

Q View related articles $₫$ 
Wagtail. - The other two species of Wagtail, namely M. alba and M. Boarula, are both indigenous here; many of the former, and a few of the latter, remaining the whole year.

Dr. Heysham in his Catalogue of Cumberland Animals, published in the year 1796, states that both these species entirely left this county in the winter; although be appears to have had some doubts with respect to $M$. Boarula, from the following observation: "Appears in Cumberland in the spring, and leaves it in October or November; and in very mild winters, a few, I believe, remain with us the whole year. I saw two on the 5th of January this year between the bridges." For some years past $I$ have paid considerable attention to the subject, and I am satisfied that some of both remain here even during our most severe winters. In confirmation of which, I have observed both on the several days mentioned below, and have added to each the minimum height of the thermometer.

\begin{tabular}{|c|c|c|c|c|c|}
\hline 24. & December & $\begin{array}{r}5 \ldots 16^{\circ} \\
23 \ldots 24 \frac{1}{2}\end{array}$ & 1826. & $\begin{array}{l}\text { November } \\
\text { December }\end{array}$ & $\begin{array}{l}27 \ldots 22^{\circ} \\
27 \ldots .27\end{array}$ \\
\hline 825. & January & $\begin{array}{r}6 . .25 \\
23 . .25\end{array}$ & 1827. & January & $\begin{array}{r}4 \ldots 13 \\
27 \ldots 16\end{array}$ \\
\hline & $\begin{array}{l}\text { February } \\
\text { November }\end{array}$ & $\begin{array}{r}5 \ldots 20 \\
12 \ldots 20\end{array}$ & & $\begin{array}{l}\text { February } \\
\text { November }\end{array}$ & $\begin{array}{r}20 \ldots .16 \frac{1}{2} \\
24 \ldots 20 \frac{3}{4}\end{array}$ \\
\hline & Jan & $\begin{array}{l}10 \ldots 15 \\
14 \ldots 11\end{array}$ & 82 & $\begin{array}{l}\text { December } \\
\text { January }\end{array}$ & $\begin{array}{l}29 \ldots 22 \frac{1}{2} \\
11 \ldots 14\end{array}$ \\
\hline
\end{tabular}

In concluding these desultory observations, it may not be amiss to state that the generic and specific names made ise of above, are those adopted by Dr. Fleming in his recent History of British Animals, which contains one of the best and most natural arrangement of British birds hitherto published.

XXXI. On the Laros of Mortality, and the Intensity of Human Life. By Mr. Francis Corbaux.**

THE natural law according to which the waste of human 1 life takes place, is the principal regulator of innumerable transactions. Researches of scientific men, long before this subject of consideration had acquired its present and daily growing importance, were directed to ascertain the reality of such a law, as expressing with some degree of accuracy the comparative rates of mortality at the successive stages of our lives. Actual experience-the only guide in those researches -was resorted to, but without discrimination, the necessity of which was at first overlooked. Hence the erroneous and almost unrestricted supposition, that a law of mortality inferred

* Communicated by the Author. 
from observations made in a particular country or even limited. district, and confined to an abridged period of time, might be. applicable to all species of concerns depending on the prom bable duration of specific lives. To admit, as universal, any law of mortality whatsoever, under the present constitution of society, would be an error no less palpable. On the other hand, a very extraordinary notion, that the law of mortality had undergone a material alteration within a century, seems. to bave gained credit with many, who fail to reflect on the immutable character of all the laws of nature without exception. Let us endeavour to place these matters in their true point of view.

Our object is to establish, that no law of mortality can be considered absolute, nor otherwise than as a particular modification of some primary law of nature, in all probability undiscoverable; - that any stated law of mortality must be exclasively referable to a specific sex, and to a class of people precisely defined, according to certain general conditions under which all comprised in that class are understood to exist; - that a well-constructed law should, amongst other characteristics, exhibit in regular gradation the mathematical expressions of the intensity of life, for each year of age, so as to harmonize, with physiological observations in that respect; - and lastly, inasmuch as such intensity materially differs in the two sexes, as also variously at different years of age, - that the progressive increase or decrease of such comparative life-intensity, relative to similar ages, ought to be distinctly expressed in the law referable to the one and in the law referable to the other sex, both belonging to the same class of selection. It is only when the law is constructed on those strict principles, that it can be truly applicable, without danger of gross miscalculation.

Doubtless, the human species, in this respect like all other species of animals, when existing under the conditions best appropriated to, and most congenial with, their respective natures, are each of them subject to a primary law by which the waste of life amongst them is governed; and it is as little to be doubted that this primary law, if it could be ascended to, would exhibit the most favourable specimen possible of human life. Even under those conditions, such a law would still be liable to many modifications, depending on accident and other circumstances; the same with the brute creation, in its immense varieties, and amongst which those which are domesticated, or others most exposed to hostile enterprise, become subject to rates of mortality far different from their original determination. But a multitude of further modifications of the primary law, relative to mankind, have been introduced consequently. 
to civilization, with its attendant inequality in the distribution of social advantages and disadvantages, and to the different circumstances of climate, soil, government, mode of living, moral and temperate habits or the contrary; as also to the greater or less liability to disease and to other causes endangering life, or tending to abridge it. Hence it becomes an indispensable requisite, that any stated law of mortality should be referable to some definite class of individuals, existing under circumstances nearly common to them all. And when it is considered that the laws hitherto published, as founded upon particular sets of local observations, made at certain limited periods, differ widely from each other in all their results and deductions, - it must follow that the indiscriminate application of any specific law, to other classes of lives than the one to which it is exclusively referable, cannot fail to generate miscalculations of the utmost consequence regarding the value of contingent property, contradistinguished from that which bears the character of certainty.

It is not merely that two classes of persons, withont distinction of sex, may exist under circumstances materially different as affecting the rates of their mortality; differences of the same tendency may be no less considerable between the two sexes, though they existed under circumstances as nearly alike as could possibly be supposed. It has therefore been another error, to have admitted the application of any law of mortality to both sexes indiscriminately.

The whole course of a life, male or female, is divisible into successive periods, more or less protracted; and during each of which, the conditions of existence are maintained, with very little variation, for either sex singly considered. But those conditions necessarily undergo, in some important respects, a notable alteration, modifying not only the rates of mortality from one period to another, but also the progressive decrease of the intensity of life; nor do those periods, or natural divisions of any life, coincide as to both sexes. This consideration, more particularly belonging to the department of physiology, ought always to be kept in view when any law of mortality is constructing; but the custom has hitherto been completely to discard it. Notwithstanding the palpable absurdity of supposing, either that the waste of life, from birth to old age, was governed by any uniform law; or that males and females, whose physical constitutions and whose vocations are widely different, were subject to exactly the same rates of mortality during similar periods of their respective ages; admissions such as these have been practically proceeded upon, and pertinaciously adhered to. It would only be fastidious to enter here 
into a detail of the enormous miscalculations which have thence arisen*.

With reference to each year of age, either the fraction which measures the probability that life will endure another year, or else the corresponding quantity of living persons, out of which one death (precisely) is to occur during the same interval, will constitute two modes equally eligible of expressing the intensity of life from year to year. In both sexes, this intensity is less at the birth than at any intermediate period from that time, until an advanced age attainable only for the privileged few ; but it gradually increases, so long as the human frame acquires any further development, and whilst nature may continue its supply of additional vigour, provided that no counteracting causes enter into operation; and from the period at which such intensity has arrived at a maximum, it invariably decreases, but in modified progressions, until all probability of life's continuance becomes extinct, as far as considered in each individual. At the same time this constant decrease has its period of limitation, with reference to any considerable number of lives of the same class, and taken together; which occurs in the following manner :-

At a certain age, which may vary from the eighty-third to the ninetieth year, according to the description of a whole population or any select portion of it, an anomaly is exhibited in the shape of apparent increase, as to the intensity of life, during a few years. Not that individual lives have actually improved; but considered in the aggregate, such as were originally constituted for outliving their cotemporaries, and who continued to exist under the most favourable circumstances, ultimately stand prominent, competing amongst themselves for protracted longevity, to the exclusion of all the rest. Indeed, this natural selection of particular lives, out of a very considerable mass, repeatedly occurs among centenaries, at later periods, and according to their respective degrees of constitutional vigour; so that very little difference may appear in the probabilities of living one more year, between two individuals of whom the ages differed even to the extent of twenty years. By duly attending to this consideration, a law of mortality may be so constructed as to represent, with all possible accuracy, the progressive expenditure of human life to the utmost attainable age, and without such statement being ever at variance with recorded facts of longevity, however extraordinary.

- After analysing all the laws of mortality set forth to the present time, critical remarks upon them, and other matter connected with this subject, have been given in the "Atlas," of the 6th, $20 \mathrm{th}$, and $27 \mathrm{th}$ of April, 4th and 20 th of May, 1828.

N. S. Vol. 5. No. 27. March 1829.

When 
When the development is complete, and all additional supply of vigour has ceased, the ordinary exercise of life, even without abuse, sufficiently accounts for the constant diminution of its intensity. Life, clisengaged from the trammels of infancy, has its period of restlessness, toil and danger; but during which, nature is proportionately bountiful in other respects. It next has a period characterized by comparative calmness of the human passions, but its usual attendants are the development of diseases which were only incipient, together with an increased liability to other diseases ; and this is superseded by another period, of nearly absolute repose, in which the character of prevailing diseases has changed, and which is not incompatible with vigorous health. From the different eircumstances attendant on those periods, and on their respective subdivisions, the ratio of progressive diminution in the intensity of life is also different during each of them ; sometimes proceeding by increment, and at other times by decrement, according to the ascertainable operation of combined eauses.

To whatever class of selection any law of mortality may refer, the intensity of a female is always superior to that of a male life of similar age, until the anomalous period last mentioned; but from the characteristic difference already noticed, in the respective conditions of their existence, this superiority 'is not the same for every year of age. It is more considerable at the birth than at any future period; as evinced by the proportion of about seven deaths occurring amongst females, to eight occurring amongst males, during their first year, out of any equal number of births of each sex and belonging to a select class. This proportion of advantage, attributable to females, rapidly decreases to the sixth or seventh year, more or less, and according to the specific class; it then ascends, in regular progression, until it attains a maximum at twenty-seven years of age, or thereabouts; after which a progressive decrease again takes place, terminating with the forty-first year, when, with reference also to a select class of lives, the respective intensities are nearly on a level for both sexes. From the latter period, the same superiority is manifested in a constantly increasing progression to the seventy-fourth year, when only it commences to decline; and about the eighty-fourth, it ultimately yields the advantage to male lives.

If the comparative intensity of life, in both sexes, be not considered relatively to specific and successive ages, but in a more absolute sense, as measturable by the respective averages of forthcoming years at the birth, and usually, though impro- 
perly, termed expectation of life ${ }^{*}$; it will then appear, that the superior intensity of female lives is in a more considerable proportion amongst the inferior classes, than amongst those selected as existing under a series of circumstances generally favourable to the preservation of life at all its stages. This difference, in the aggregate, will also be conspicuous in the detail, though with some variation in the progressive ratios, and likewise in the respective periods of increase and decrease.

Any two laws of mortality, the one applicable to male and the other to female lives, both of the same class of selection, will, unless defective, present all those differences in their proper light.

With reference to either sex, a very considerable difference takes place in the maximum of intensity, as also in the year of age at which it occurs, between lives of a superior and those of an inferior class. In the instance "of lives belonging to a select class, to which the annuitants may generally be assimilated, the maximum of intensity for females, and expressed by a required quantity of the living for producing one death before the expiration of another year, is 270 , and referable to fifteen completed years of age; whilst it is 236 only for males, and referable to the age of fourteen years: and for the inferior class of either sex, involving the great mass of people who exist under circumstances of hardship and privation, the maximum thus expressed scarcely exceeds a hundred, referable to an earlier age even than that of ten years $\dagger$; after which the intensity of life, for this class, begins to decrease. Facts of this description abundantly testify how inapplicable the law of mortality must be to any other class than the one to which it expressly refers.

A principal feature, indicative of the quality of lives to which any such law may be referable, is the comparative number of population, whether general or select, and of the specified sex, that should permanently result from any given quantity of annual births, compensating an equal quantity of deaths understood to occur during the same interval. This fiction, of an absolutely stationary population, is requisite for enabling the stated law of mortality to fulfill at once two indications: first, the progressive decrement, from year to year, of indivi-

* The true expectation is the period of years at the expiration of which the living, at any stated age, will be reduced to half their number; thereby indicating an equal probability of outliving that period or not.

+ These remarks are not stated with greater precision, because the liw applicable to the inferior class alluded to (being the ffth and last) is not yet completed. 
duals remaining alive, out of the quantity supposed annually to be born; and secondly, the absolute quantity of the living, at each year of age: which quantities constitute the distribution of the whole comparative population just mentioned.

Whilst the greater superiority of the selected class necessarily produces the greater sum of permanent population, as arising from any common radix of annual births, that relative sum, also regulating the average of forthcoming years that belong to each infant born, differs less, as regards the contradistinguished sexes, than it does in case of lives of an inferior quality. If $2 \frac{3}{4}$ years' difference in that average takes place from one sex to the other, respecting a class selected as perfect, that quantity will extend to 3 years for a second class to which the life-annuitants may be assimilated; to $3 \frac{1}{4}$ for a third class, or that of assurable lives; to $3 \frac{1}{2}$ for the general population of such countries as Great Britain or France, and even to four years for the inferior qualities of lives amongst that general population.

'The superior intensity, thus measured, of one class of lives over another, without regard to difference of sex, is mostly derived from the circumstances that attend early stages of life. When, on the contrary, infancy is subject to unfavourable conditions of existence, no consideration of comparative healthiness at subsequent ages, or of remarkable longevity amongst the survivors, could afford any adequate compensation for the curtailment resulting, in the population, from a deficiency of wholesome subsistence, or of proper care towards the maintenance of health, during infancy. In one country or district, where those advantages are fully enjoyed, though from other circumstances the rates of mortality should become very elevated after the meridian of life is passed, the comparative population growing out of an equal quantity of annual births, may be as three to troo, with that of another country or district in which infancy suffered privation and neglect; though from advantageous circumstances of climate and soil in the latter, the mortality proceeded at a very slow pace amongst the survivors, and the observation of facts tended to establish there at very high rates the expectation of life in old age. This again gives warning of the caution with which data, merely local or circumstantial, ought to be admitted, and of the errors likely to follow an extended application of them.

Nevertheless, the data now possessed towards constructing a law of mortality applicable to either sex and of any specific class, are sufficient for obtaining very satisfactory results; provided they are judiciously employed, and that their comparison be governed by an attentive consideration of physiological principles. 
principles. The problem then to be solved, is that of distributing with all possible accuracy, according to those principles, and relatively to the circumstances under which any population or select class is acknowledged to exist, the comparative total of such population (supposed stationary) or class as arising from a stated quantity of annual births.

5, Hercules' Buildings, Lambeth. 7th Nov. 1828.

XXXII. Some Arguments tending to prove that the Earth is a Solid of Revolution. By JaMes IVor Y, Esq. M.A. F.R.S.\&c.*

IN the investigation of the figure of the earth, the first point I that engages attention, is to determine the nature of the meridians. Are these all equal and similar curves? or are they variable or irregular in their form? It can hardly be expected that these questions can be answered with the strictest mathematical precision. There will occur, it is likely, discrepancies caused both by local circumstances and by the want of perfect exactness in the data of observation. But at the same time that, in every particular measurement, the greatest care must be taken to insure the utmost degree of accuracy compatible with experimental operations, we must likewise endeavour to deduce some general conclusion from a comparison of the whole series of individual results, and to form a general notion of the figure of the earth, overlooking local and casual irregularities. Unless we thus attempt to generalize the knowledge we obtain, the inquiry, it is evident, would lose much of its interest and utility. The most probable inference that we can at present draw from the best measurements that have been made, is that the meridians are equal and similar ellipses, the difference of the two semi-axes being about $\cdot 00324$ of the equatorial semi-diameter.

But if the meridians be equal and similar ellipses, the earth must necessarily be an oblate spheroid of revolution. And there are not wanting arguments that very forcibly confirm this inference. In all times, past and present, it has been assumed that a terrestrial meridian is a plane containing the earth's axis; and likewise that a plumb-line, or a perpendicular to the earth's surface, lies wholly in one plane with the same axis. All astronomy is built on these suppositions, and no grounds have ever occurred that make their accuracy questionable. Now the properties we have mentioned belong ex-

- Communicated by the Author. 